\title{
Pediatric patients' head-up-tilt-test with pharmacological challenge, it is safe?
}

\author{
Mesa inclinada en pacientes pediátricos con reto farmacológico, ¿es seguro? \\ Alan García1, Gabriela A. Bustillos-García1*, and Leonardo Rivera-Roodríguez² \\ ${ }^{1}$ Department of Electrophysiology; ${ }^{2}$ Department of Pediatric Cardiology, Instituto Nacional de Cardiología Ignacio Chávez, Mexico City, Mexico
}

\begin{abstract}
Syncope in pediatrics represents an important cause of visits to the emergency units. For this reason, excluding a cardiac or malignant origin is essential at the time of the initial approach to determine what is the next step in management, or if they need to be referred to a pediatric cardiologist and/or electrophysiologist. Vasovagal syncope is the most frequent cause of syncope in pediatrics, in which a detailed clinical history is enough to make the diagnosis. If no diagnosis is concluded by the history, or if it is necessary to define the hemodynamic response of the patients, the head-up-tilt-test is indicated; this will trigger syncope due to an orthostatic stress caused by the angulated table (passive phase). If a negative response remains, it can be followed by a pharmacologic challenge to trigger the hemodynamic response, which is still controversial in pediatrics. The pharmacologic challenge increases the sensitivity with a slight reduction in test specificity. Although there is not a specific drug for the challenge in pediatric patients yet, the most commonly drugs used are nitrates and isoproterenol, the latter related to a great number of adverse effects. Sublingual administration of nitrates in the challenge has been proven to be ideal, effective, and safe in this specific age group. The aim of this article is to make a literature search to demonstrate the effectiveness and safety of the pharmacologic challenge during the head-up-tilt-test in pediatrics, emphasizing a study conducted at the National Institute of Cardiology with isosorbide dinitrate.
\end{abstract}

Key words: Head-up-tilt-test (tilt-test). Isosorbide dinitrate. Syncope.

\section{Resumen}

El síncope en edades pediátricas representa una causa importante en las visitas a unidades de urgencias, por lo que excluir un origen cardíaco o maligno es fundamental al momento del abordaje inicial para determinar la conducta a seguir o la necesidad de derivar al cardiólogo pediatra o electrofisiólogo. El síncope vasovagal (SVV) es la causa más frecuente de síncope en pediatría, para cuyo diagnóstico basta una historia clínica detallada. Cuando ésta no es suficiente para determinar el diagnóstico de síncope reflejo o es necesario definir el tipo de respuesta que lo origina, está indicada una prueba de mesa inclinada que produce un estrés ortostático por la angulación y ello desencadena un síncope (fase pasiva). En pruebas no concluyentes está indicado un reto farmacológico para precipitar la respuesta hemodinámica, pero aún es un tema de controversia en edades pediátricas. El reto farmacológico incrementa la sensibilidad de la prueba, con una ligera reducción de la especificidad. Si bien no existe todavía un medicamento específico para la población pediátrica, los más empleados son

\section{Correspondence:}

*Gabriela A. Bustillos-García

E-mail: gabustillos@gmail.com
Available online: 04-09-2020 Arch Cardiol Mex (Eng). 2020;90(2):163-172 www.archivoscardiologia.com 2604-7063 / @ 2019 Instituto Nacional de Cardiología Ignacio Chávez. Published by Permanyer. This is an open access article under the CC BY-NC-ND license (http://creativecommons.org/licenses/by-nc-nd/4.0/).

Date of reception: $18-06-2019$

Date of acceptance: 21-10-2019

DOI: 10.24875/ACME.M20000111 
los nitratos y el isoproterenol, este último relacionado con un mayor número de efectos adversos. La administración sublingual de los nitratos utilizados ha demostrado ser ideal, efectiva y segura en los pacientes pediátricos. El objetivo del artículo es realizar una revisión de las publicaciones médicas que demuestran la efectividad y seguridad del reto farmacológico durante la prueba de mesa inclinada en pacientes pediátricos, con énfasis en un estudio conducido en el Instituto Nacional de Cardiología con dinitrato de isosorbida (DNIS).

Palabras clave: Dinitrato de isosorbida (DNIS). Prueba de mesa inclinada. Síncope.

\section{Introduction}

Syncope is a common problem in pediatrics that accounts for $1 \%$ of visits to the Pediatric Emergency Department ${ }^{1}$. Annual incidence is calculated at $1.25 / 1000$ pediatric patients, and it is more common in children older than 10 years ${ }^{2}$. Recurrent syncope can markedly affect patient quality of life due to the stage of development he/she is in.

Syncope is generally defined as transient loss of consciousness secondary to cerebral hypoperfusion, characterized by its sudden nature, and sometimes it is preceded by short-lived prodromes (pre-syncope symptoms), almost always with spontaneous and complete recovery without post-event states of confusion. However, cerebral hypoperfusion can generate seizure-like movements, especially of the tonic-clonic or myoclonic type, followed by short periods of amnesia; this can confuse the doctor during interrogation, particularly when the episode was not witnessed by someone else that helps clarify the clinical scenario of the syncope $^{3}$ (Fig. 1).

On the other hand, pre-syncope is defined as a sensation of loss of consciousness without reaching it and is characterized by secondary symptoms of both hypoperfusion and parasympathetic stimulation, such as sweating, paleness, nausea, vomiting, blurred vision, and among others ${ }^{4}$. Although the definition of syncope is not clearly established when talking about a neuro-cardiogenic origin secondary to a transient dysfunction of the autonomic nervous system that occurs in the pediatric population, there are still several terms for refer to it, including "fainting," "vasovagal syncope (VVS)," "reflex syncope," and "neuro-cardiogenic syncope."

Among the causes of syncope, vasovagal etiology affects $15 \%-25 \%$ of children and adolescents and is the most common cause of syncope in the pediatric population $\left(61-80 \%\right.$ of cases $\left.^{5,6}\right)$.

Due to the complexity of syncope, it is essential for a detailed medical history to be obtained during patient initial approach, which can be diagnostic for VVS without any other complementary study being required. Similarly, an extensive approach is necessary to rule
Table 1. Common causes of transient loss of consciousness in children

\begin{tabular}{|c|c|}
\hline $\begin{array}{l}\text { Causes of syncope } \\
\text { ordered by frequency }\end{array}$ & Example \\
\hline Vasovagal syncope & $\begin{array}{l}\text { Typical: prodrome symptoms } \\
\text { Atypical: no prodrome symptoms }\end{array}$ \\
\hline Breath-holding spells & $\begin{array}{l}\text { Brief periods in which the children } \\
\text { stop breathing, with duration of up to } \\
1 \text { min, } \\
\text { secondary to emotions such as anger, } \\
\text { surprise, or injury }\end{array}$ \\
\hline Heart-related & $\begin{array}{l}\text { Primary electrical disturbances } \\
\text { - Long OT syndrome } \\
\text { - Short QT syndrome } \\
\text { - Brugada syndrome } \\
\text { - Wolff-Parkinson-White (WPW) } \\
\text { syndrome } \\
\text { - Catecholaminergic polymorphic } \\
\text { ventricular tachycardia } \\
\text { Heart structural alterations } \\
\text { - Hypertrophic cardiomyopathy } \\
\text { Coronary artery abnormalities } \\
\text { - Right ventricular arrhythmogenic } \\
\text { dysplasia } \\
\text { - Aortic valve stenosis } \\
\text { - Dilated cardiomyopathy } \\
\text { - Pulmonary hypertension } \\
\text { - Acute myocarditis }\end{array}$ \\
\hline Neurological & $\begin{array}{l}\text { Seizures } \\
\text { - Panayiotopoulos syndrome } \\
\text { Vascular episodes } \\
\text { - Subclavian steal phenomenon } \\
\text { - Vertebrobasilar insufficiency } \\
\text { Cerebrospinal fluid impaired circulation } \\
\text { - Third ventricle colloid cyst } \\
\text { - Tumors of the posterior fossa } \\
\text { Vertigo crisis } \\
\text { Basilar migraine } \\
\text { Narcolepsy/cataplexy } \\
\text { Bleeding, dehydration, hypoglycemia, } \\
\text { hydroelectrolytic abnormalities. } \\
\text { Conversion syndrome, somatization, } \\
\text { Munchausen syndrome/pretending the } \\
\text { disease (malingering) } \\
\text { Anxiety and hyperventilation syndrome }\end{array}$ \\
\hline Unk & \\
\hline
\end{tabular}

out other causes such as primary origin, including heart conditions of obstructive or arrhythmogenic types, or neurological, and metabolic diseases ${ }^{7,8}$ (Table 1). 


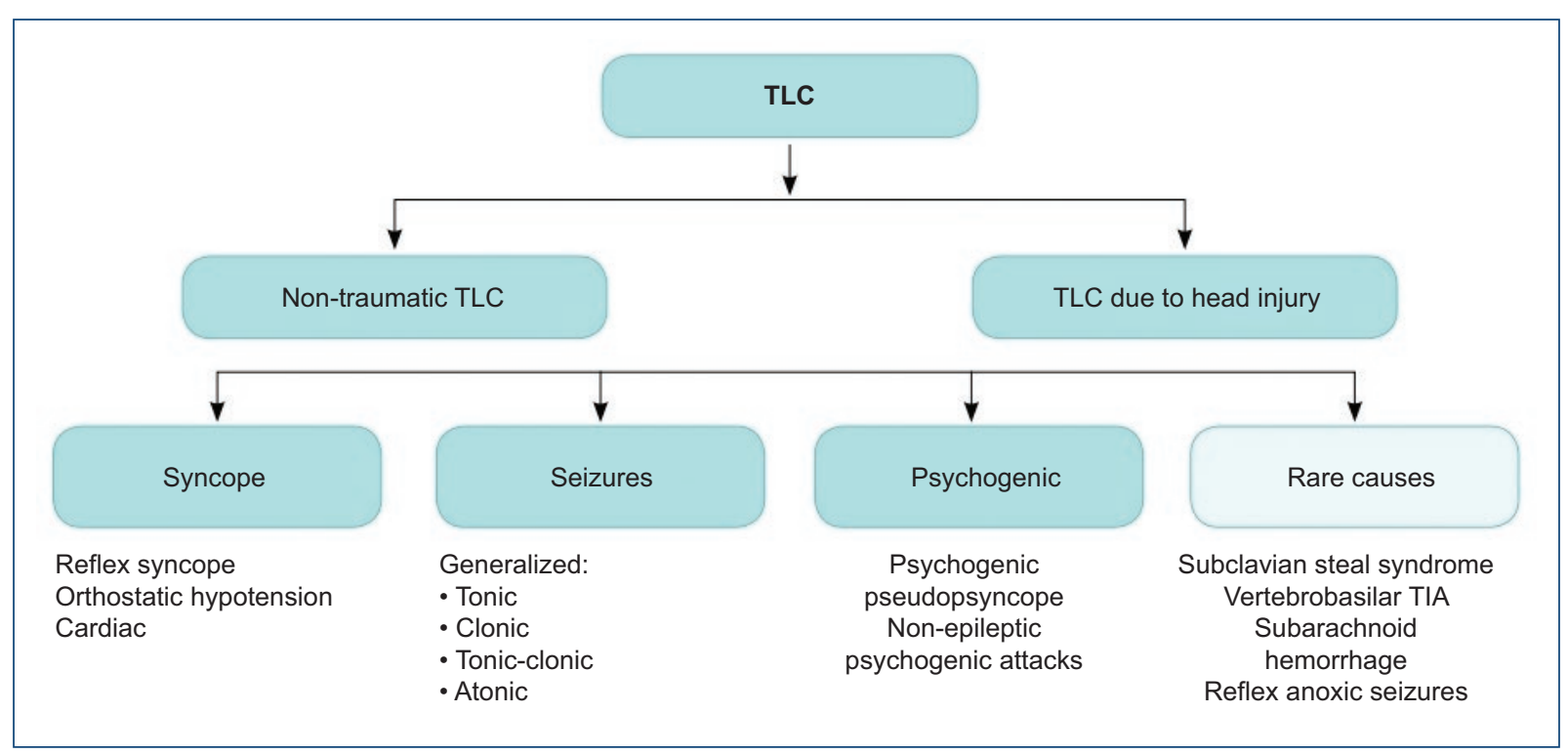

Figure 1. In the context of non-traumatic loss of consciousness, the disorder is classified in four groups: syncope, epileptic seizures, transient psychogenic loss of consciousness and diverse origins (rare causes). Non-traumatic loss of consciousness can cause falls with subsequent trauma, in which case loss of consciousness is traumatic and nontraumatic. (With permission of 2018 ESC Syncope Consensus).

When there is diagnostic doubt and other causes of syncope have been previously ruled out, it is necessary to perform a head-up-tilt-test to verify the vasovagal origin through a vasodepressor or cardioinhibitory response ${ }^{2,9}$.

\section{Head-up-tilt-test}

Head-up-tilt-test is a useful, low cost tool that allows the diagnosis of reflex syncope to be established when it is uncertain. Although most studies are carried out in adults, its safe use has been documented in the pediatric population ${ }^{10}$. This test should not be used with the purpose to induce or assess the response to pharmacological or interventional treatment in the patient with VVS due to low reproducibility of the test for triggering the same hemodynamic response in a second test ${ }^{2,6}$.

Initially, head-up-tilt-test only included a passive phase, and orthostatic stress was triggered by tilting the table. Subsequently, the so-called "method of symptoms" was used, which through carotid massage increased vagal tone until culminating in syncope secondary to a vasodepressor or cardioinhibitory response $^{11}$. Finally, the provocation or pharmacological challenge phase was developed, and the "Italian protocol" is one of the mainly used: it uses glycerol trinitrate to demonstrate a positive response for syncope more quickly and to shorten not only the duration of the test, but it also increases its sensitivity with a slight specificity reduction ${ }^{12}$.

Subsequently, different protocols modified some factors such as duration of the phases, both the passive phase and the pharmacological challenge, and they also used different drugs in the latter looking to increase the sensitivity and specificity of the test ${ }^{13}$.

\section{Head-up-tilt-test methodology}

Head-up-tilt-test should be carried out in a comfortable, relaxed environment and away from noise to avoid false positives and negatives. Before starting the procedure, it is important to know if the patient is allergic to the drugs used in the pharmacological challenge if necessary. The patient must be under continuous monitoring through an electrocardiogram before starting the test and cardioinhibitory response being evaluated, since some may experience syncope due to the puncture. On the other hand, a plethysmograph placed on a finger or cuff-type on a limb documents the vasodepressor component.

The head-up-tilt-test has two phases: in the first one, called passive (unprovoked), it is recommended for the table to be tilted at an angle between $60^{\circ}$ and $70^{\circ}$, because higher or lower angles have been shown reduce the sensitivity and specificity of the test ${ }^{3.14}$. This phase lasts from 20 to $40 \mathrm{~min}$, which is time enough to cause 
Table 2. Types of hemodynamic response on the tilt table

\begin{tabular}{|c|c|}
\hline $\begin{array}{l}\text { Type of response on the } \\
\text { tilt table }\end{array}$ & Response characteristics \\
\hline Type 1 or mixed & $\begin{array}{l}\text { Heart rate drops at the moment } \\
\text { the syncope occurs, but not }<40 \\
\text { bpm; drop lasts }<10 \mathrm{~s} \text {. BP drops } \\
\text { prior than HR }\end{array}$ \\
\hline $\begin{array}{l}\text { Type 2A (cardioinhibitory } \\
\text { without asystole) }\end{array}$ & $\begin{array}{l}\text { Heart rate drops }<40 \mathrm{bpm} \text {, for } \\
\text { more than } 10 \mathrm{~s} \text {. } \\
\text { BP drops before HR }\end{array}$ \\
\hline $\begin{array}{l}\text { Type 2B (cardioinhibitory } \\
\text { with asystole) }\end{array}$ & $\begin{array}{l}\text { Asystole with }>3 \text {-s duration. Drop } \\
\text { in blood pressure coincides with } \\
\text { or is subsequent to that of HR }\end{array}$ \\
\hline Type 3 or vasomotor & $\begin{array}{l}\text { HR drop does not exceed } 10 \% \text { in } \\
\text { comparison with the peak at the } \\
\text { moment of syncope }\end{array}$ \\
\hline $\begin{array}{l}\text { Chronotropic } \\
\text { incompetence }\end{array}$ & $\begin{array}{l}\text { No significant increase in HR } \\
\text { during tilt (e.g., }<10 \% \text { of HR } \\
\text { before tilt) }\end{array}$ \\
\hline $\begin{array}{l}\text { Postural orthostatic } \\
\text { tachycardia syndrome } \\
\text { (POTS) }\end{array}$ & $\begin{array}{l}\text { Exercise increases HR (> } 130 \\
\text { bpm), at the beginning and during } \\
\text { the tilt, before the syncope }\end{array}$ \\
\hline
\end{tabular}

HR: heart rate; bpm: beats per minute; BP: blood pressure

orthostatic stress. The passive phase is still the firstline in the tilt test. When it remains negative and concluding a diagnosis is still required, the procedure is continued with a second phase with pharmacological challenge (provoked phase) for 10-20 min, with various nitrates or isoproterenol being used in the vast majority of protocols.

At the National Institute of Cardiology (Mexico), the tilt test is performed at an angle of $70^{\circ}$ in the passive phase for $20 \mathrm{~min}$, followed by a provocative phase when a diagnosis is not yet established, and $5 \mathrm{mg}$ isosorbide dinitrate is used for $12 \mathrm{~min}$, which allows enough time to trigger the syncope.

The test is considered positive when the patient reproduces symptoms of syncope or hypotensive or cardioinhibitory response or both are documented, with return of the patient to a Trendelenburg position within 10-15 s and spontaneous recovery. At conclusion, it is classified according to the predominant hemodynamic response, either vasodepressor, cardioinhibitory, or mixed (Table 2); in addition, the test allows diagnosing other causes of syncope, such as orthostatic hypotension $(\mathrm{OH})$ or postural orthostatic tachycardia syndrome (POTS). The classification confers clinical meaning to the tilt test (Table 3), with a variable positivity rate (Fig. 2).
Table 3. Tilt test clinical Interpretation (warnings regarding interpretation of the result on the tilt table)

Clinical meaning according to the result on the tilt table

- A negative head-up-tilt-test does not exclude reflex syncope diagnosis

- Despite tilt test sensitivity and specificity with regard to the presence of susceptibility to hypotension, which may not only be present in reflex syncope but also in other causes of syncope, including those of cardiac origin. The concept of susceptibility to hypotension, rather than being a diagnosis, has important clinical usefulness, given that its absence or presence play an important role for directing treatment toward pacemaker in patients affected with reflex syncope and in the control of hypotension, which is more common in elderly patients

- A positive cardioinhibitory test on the tilt table predicts with high probability the presence of syncope with spontaneous asystole; this is an important finding due to the implication of considering pacemaker in the treatment of these cases. The presence of a vasopressor response or mixed response does not exclude that the patient suffers from asystole during spontaneous syncope periods

- The tilt test is useful to separate the syncope that occurs with seizures in patients who experience abnormal movements due to epilepsy

- The tilt test has value to distinguish the syncope of patients who only suffer falls

- The tilt test is useful to separate the syncope from the psychogenic pseudosyncope. In patients with suspected psychogenic pseudosyncope, the tilt test is performed in conjunction with an EEG to monitor and confirm the diagnosis

- The head-up-tilt-test should not be used to assess treatment efficacy

EEG: electroencephalogram

Although there is still no reference standard for the diagnosis of syncope, head-up-tilt-test remains the most widely used method for diagnostic purposes ${ }^{3,15}$. Nevertheless, given that, usually, the documented standards of the test come from studies on adult subjects, there is no specific methodology for pediatric patients. It has been documented that, in the latter, it is enough with 10-min test periods at an angulation of the table from $60^{\circ}$ to $70^{\circ}$ to precipitate the syncope, and a specificity of $85 \%$ has been demonstrated ${ }^{16}$.

\section{Indications}

1. To confirm the syncope diagnosis in patients in whom it has not been confirmed or to reproduce the symptoms referred by the subject, with hemodynamic pattern determined after initial evaluation ${ }^{3}$. 


\begin{tabular}{|c|c|}
\hline \multicolumn{2}{|c|}{ Tilt test: positive response rates } \\
\hline $92 \%$ & $\begin{array}{l}\text { Typical VVS, emotional trigger } \\
(\text { Clom })^{126}\end{array}$ \\
\hline $78 \%$ & $\begin{array}{l}\text { Typical VVS, emotional trigger } \\
(\text { TNG) })^{126}\end{array}$ \\
\hline $73-65 \%$ & $\begin{array}{l}\text { Typical VVS, miscellaneous } \\
(\text { (Clom })^{127}\end{array}$ \\
\hline $56-51 \%$ & $\begin{array}{l}\text { Probably reflex, atypical } \\
(\text { TNG })^{128,129}\end{array}$ \\
\hline $47 \%$ & Cardiac syncope (TNG) $)^{129}$ \\
\hline $45 \%$ & $\begin{array}{l}\text { Probably tachyarrhythmic syncope } \\
\text { (passive })^{120}\end{array}$ \\
\hline $36-30 \%$ & $\begin{array}{l}\text { Syncope of unknown cause } \\
(\text { TNG })^{126,127}(\text { Clom })^{126}\end{array}$ \\
\hline $13-8 \%$ & $\begin{array}{l}\text { Subjects without syncope } \\
(\text { passive })^{125}(\text { Clom })^{124}(\text { TNG })^{106}\end{array}$ \\
\hline
\end{tabular}

Figure 2. Head-up tilt test positivity rate in different clinical conditions. These studies used the Westminster protocol for passive tilt, the Italian protocol for tilt with trinitroglycerin and the clomipramine protocol for a total of 1,453 patients with syncope and 407 controls without syncope. Studies using other protocols were not included. (With permission of the 2018 ESC Syncope Consensus). Clom: clomipramine; TNG: trinitroglycerin; VVS: vasovagal syncope.

2. To assess the autonomic failure causative of $\mathrm{OH}$, either due to suspicion or confirmation of changes in blood pressure during initial evaluation ${ }^{3}$.

3. To diagnostically confirm the presence of POTS ${ }^{3}$.

4. To differentiate in case of clinical suspicion of psychogenic pseudosyncope with regard to another cause of syncopal origin ${ }^{3}$.

\section{Contraindications}

Contraindications to the test include severe mitral stenosis, diseases that cause obstruction of the left ventricular outflow tract, arterial cerebral disease, and severe coronary artery disease ${ }^{17}$.

\section{Pharmacological challenge on the tilt table in pediatric patients}

One of the fears when performing the head-up-tilt-test in pediatric patients has been the false positive results obtained in some cases, due to patient lack of cooperation, fear of the test, separation from the parents on admission to the test, which arouses anxiety and crying, as well as doctor's fear of drug-related secondary reactions and asystole periods, which are more alarming the longer they are. Although asystole duration is not related to disease severity and most subjects spontaneously recover the state of alertness after lowering the bed to the supine position, secondary episodes of cardiorespiratory arrest have been documented ${ }^{18,19}$.

Pharmacological challenge has been highly useful and has increased the sensitivity and specificity of the test. However, controversy continues regarding which drug is most useful for this age group due to the wide variety of results and the paucity of specific studies; isoproterenol and nitrates are the most widely used drugs.

\section{Isoproterenol}

Most adverse effects on the tilt test with pharmacological challenge have been attributed to the use of isoproterenol ${ }^{13,20}$. Cases of acute myocardial infarction and ventricular arrhythmias have been reported during isoproterenol administration in the pharmacological challenge; however, these were recorded in patients $>60$ years $^{21}$. Another relevant point regarding isoproterenol administration route is that intravenous instrumentation can trigger syncope and confound the results ${ }^{22}$.

Lai et al. carried out a study in 79 pediatric patients (age range, 5.5-18 years) divided in two groups: the first one, with VVS clinical diagnosis (65 patients), and the second, without clinical data consistent with VVS (14 patients). Both groups underwent head-up-tilt-test, which consisted of a first phase without pharmacological challenge, followed by a challenge with isoproterenol infusion in patients who during the first phase did not trigger syncope. Up to 29 patients in Group 1 and two in Group 2 required pharmacological challenge to determine the syncope origin and type of response. Group 2 showed various medically adverse effects: two patients suffered ventricular arrhythmias, one required pacemaker secondary to a second degree blockade and the rest experienced ventricular extrasystoles. It was concluded that isoproterenol infusion increased the sensitivity of the test by up to $45 \%$, and specificity decreased slightly from $93 \%$ to $86 \%{ }^{23}$. However, drug infusion duration (30 $\mathrm{min}$ ) and dose used in this protocol $(0.5-1 \mu \mathrm{g} / \mathrm{min}) \mathrm{might}$ have caused an increase in the number of false positives during the test.

A shorter infusion duration and an isoproterenol dose between 0.5 and $5 \mu \mathrm{g} / \mathrm{min}$ have been reported to be enough to precipitate symptoms, which prevents a larger number of erroneous results ${ }^{24,25}$. 


\section{Nitrates}

The first studies by Dindar et al. showed an increase in the sensitivity of the test with the use of Integrated Services Digital Network (ISDN) in comparison with the passive phase alone, with an increase in sensitivity to $77.5 \%$ with regard to $15 \%$, and a slight change in specificity, $91.6 \%$ versus $100 \%$, respectively ${ }^{26}$. Subsequently, Karacan et al. demonstrated similar results in a study carried out in 29 patients where ISDN was compared with the conventional test without pharmacological challenge, an increase in sensitivity was recorded $(96.7 \%$ vs. $30 \%)$, with a slight reduction in sensitivity ( $93.3 \%$ vs. $100 \%$, respectively), without serious side effects being demonstrated, and thus it can be indicated as an effective and safe method ${ }^{27}$.

\section{Comparative studies}

Sensitivity $(50-80 \%)$ with the use of nitroglycerin is similar to that demonstrated with isoproterenol administration (60-85\%) in various studies. However, despite the specificity reduction in the pharmacological challenge, specificity is $85-95 \%$ with nitroglycerin in comparison with isoproterenol, with a specificity reduction from $35 \%$ to $83 \% 24,28-32$.

Even though Swissa et al., in a comparison of 136 patients undergoing pharmacological challenge in the tilt test with isoproterenol, relative to ISDN, demonstrated that the use of the latter caused a larger number of bradyarrhythmias and longer asystolic response duration, only one case of cardiorespiratory arrest with recovery after rescue maneuvers was reported ${ }^{33}$. Various comparative studies have shown a larger number of positive responses to the test in up to $12 \%$ with nitroglycerin, as well as better tolerance and fewer adverse effects in comparison with the use of isoproterenol ${ }^{34,35}$. In another study carried out at the National Institute of Cardiology in Mexico City, which is described below, the safe and effective use of said test (ISDN was used) was demonstrated in a larger patient cohort. Similarly, nitroglycerin sublingual use in the provocation phase of the test, especially in pediatric patients, prevents intravenous administration from increasing both patient psychological stress and false-positive results.

\section{Study conducted in patients of the National Institute of Cardiology}

A retrospective analysis of head-up-tilt-test results was carried out at Ignacio Chávez National Institute of
Cardiology in patients aged $\leq 18$ years with a clinical history indicative of VVS or syncope of unknown origin, between 2015 and 2018. There were 220 patients included, who were divided in two age groups: Group 1, < 10 years (36 patients), and Group 2, from 10 to 18 years of age (183 patients). No predominant gender was observed in either group. In 179 patients (83\%) of the total sample, pharmacological challenge was necessary in the tilt table test to determine their hemodynamic response. The positive response rate of the entire sample was $66 \%$ (Group 1, 50\%; Group 2, 70\%). In both groups, the hemodynamic responses pattern that predominated was the mixed type (Group 1, 50\%, Group 2, 56\%).

\section{Group I}

Thirty-six patients, with an age range of $6-10$ years (mean of 7.8). The gender ratio was 1.25:1 (20/16) in favor of the male gender. Main indication for the test was syncope in 23 patients, followed by pre-syncope in 13 patients. The test was positive in 18 patients, three showed positive response during phase 1 (without pharmacological challenge) and the rest required ISDN administration. Response time ranged from 4 to 12 min, with an average of 9.3. Predominant hemodynamic response was of the mixed type in 9 patients (50\%), followed by dysautonomia (4) and cardioinhibitory $2 B$ response (4) with pauses ranging between 3 and $6 \mathrm{~s}$; only one patient had a cardioinhibitory $2 \mathrm{~A}$ response.

\section{Group II}

One hundred and eighty-three patients aged between 11 and 18 years (mean, 14.8). No gender difference was observed (1:1 ratio). The test was positive in 128 patients $(70 \%), 31$ during phase 1 and the rest required ISDN sublingual administration. Response time during the test was variable, from 1 to $20 \mathrm{~min}$, with a mean of $8.5 \mathrm{~min}$. The predominant hemodynamic response was of the mixed type in 43 patients (33.7\%), followed by dysautonomia in 32 patients (25\%), cardioinhibitory $2 \mathrm{~B}$ in 25 patients (19.5\%), vasodepressor in 14 patients $(11 \%)$, cardioinhibitory $2 \mathrm{~A}$ in 13 patients $(10 \%)$, and only one patient experienced POTS $(0.8 \%)$.

In all asystole cases during the test, recovery was achieved after positioning the patient in the supine position and administering fluid therapy. No complications were recorded during the study. This test demonstrates, 
like others already mentioned, the safe use of sublingual ISDN in pediatric patients.

\section{Treatment}

\section{NON-PHARMACOLOGICAL MEASURES}

In children with VVS, preventive measurements are still the first-choice treatment and include reassuring the patient (he/she is indicated that the procedure is benign and that it has the purpose to reduce psychological stress), avoiding syncope-triggering factors and increasing salt ingestion ( $2 \mathrm{~g} /$ day); fluids ( $3 \mathrm{~L}$ daily) reduce such episodes ${ }^{36}$. Training through physical maneuvers that increase venous return and orthostatic tolerance have been shown to be effective to revert syncope $^{37,38}$. Various clinical studies have demonstrated the effectiveness of non-pharmacological treatment and have reduced syncope recurrence from $56 \%$ in untreated patients to $39 \%$ when fluid and salt consumption was increased $(p=0.029)^{39}$. It is essential to emphasize the importance of discipline in dietary changes (water and salt ingestion) and physical training to prevent syncope in pediatric patients. Recently, a cross-sectional study was carried out in 70 patients aged from 5 to 20 years, divided in two groups; Group 1 was made up of 30 patients ( 13 males/17 females) who received pharmacological and non-pharmacological measures and was compared with Group 2, which included 40 patients (18 males/22 females) treated only with non-pharmacological measures (increase of dietary water and salt, physical maneuvers). Both groups were followed up for 3 years, and a significant difference was observed in pre-syncope and syncope symptoms in those patients only non-pharmacologically treated (Group 2), with a 3-year recurrence rate of 5\% in comparison with patients who combine the same treatment with pharmacological measures (Group 1), in whom syncope recurrence was $44 \%(p=0.001)$; it should be mentioned that the obtained results may be due to the fact that patients undergoing pharmacological and non-pharmacological treatments tend to reduce follow-up and correct use of the latter; it is thus concluded that correctly-used preventive measures is enough for the treatment of patients with neuro-cardiogenic syncope ${ }^{40}$.

\section{Pharmacological measures}

The use of drugs for the treatment of VVS should be considered as second line in pediatric patients in whom syncope recurrence continues despite preventive measures correct use. The most widely used medications include beta-blockers, midodrine ( $\alpha$ receptor agonist), fluorohydrocortisone, and serotonin reuptake inhibitors; however, the ideal drug has not yet been found due to the low response to treatment. Despite this, although there are only few studies of midodrine treatment in pediatric patients, they have shown high effectiveness in syncope reduction. A randomized study was carried out in 26 patients with ages ranging between 6 and 16 years, who were divided into two groups: Group 1, with 13 patients who were treated with midodrine and non-pharmacological measures, and Group 2 (13 patients), which was treated only with non-pharmacological measures, for a short follow-up of 6 months. A reduction in conservative treatment-resistant VVS recurrence was demonstrated, with a recurrence rate of $80 \%$ in Group 1, in comparison with $22 \%$ in patients treated with midodrine $(p=0.023)$. No supine hypertension was observed in any of the subjects treated with midodrine and only one experienced gastrointestinal discomfort during treatment ${ }^{41}$. In a second study, conducted in 48 patients aged 6-17 years with syncope or pre-syncope symptoms, the participants were randomly assigned to three groups to compare different treatments. Group 1 included individual treated with non-pharmacological measures; Group 2, subjects with cresol-based treatment (placebo); and Group 3, patients treated with midodrine, each group made up of 16 patients, during an approximate follow-up of 9 months. It was concluded that midodrine was effective in reducing syncope when compared to the other treatments used $(p=0.05)^{42}$. Despite the results of both studies, the follow-up short duration, as well as treatment response assessment by repeating the head-uptilt-test, limit the obtained results, since the guidelines indicate the modest usefulness of the latter for therapeutic evaluation ${ }^{3}$. Another possibility for the demonstrated effectiveness might be secondary to the type of predominant hemodynamic response (vasodepressor), which is correlated with a higher effectiveness rate when using an $\alpha_{1}$ receptor agonist drug ${ }^{41}$.

Evidence of fluorohydrocortisone benefit is limited because there are only few studies conducted in this age group. A randomized, double-blind, and placebo-controlled study was conducted in 32 patients (one was lost to follow-up during the study), all aged $<18$ years. Group 1 included 18 patients treated with salt supplements and fluorohydrocortisone, and Group 2 (14 patients) received placebo, with an approximate follow-up of 1 year. Conversely to the hypothesis raised 
in favor of the use of fluorohydrocortisone, subjects in the placebo group were found to have lower syncope recurrence $(p=0.04)$, and only $53 \%$ of total treated patients did not suffer syncope during follow-up; therefore, low effectiveness of the employed drug was observed $^{43}$. These results are similar to those of a comparative study between fluorohydrocortisone $(0.2 \mathrm{mg} / \mathrm{day})$ and atenolol (100 mg/day) for the treatment of VVS, where the recurrence rate was $52 \%$ (30 patients) of total subjects treated in both groups (a total of 58 individuals $)^{44}$.

Beta-blockers remain a treatment with a Class III recommendation (no benefits) for pediatric patients, according to syncope treatment guidelines ${ }^{3,16}$, despite the fact that a reduction of $60 \%$ in recurrent syncope was initially demonstrated in 21 patients treated with metoprolol $^{45}$. Subsequently, in a prospective, randomized study, carried out in patients aged 8-17 years, with a 1-year follow-up, treatment with metoprolol was shown to be related to a higher syncope recurrence rate in comparison with non-pharmacological treatment, $43 \%$ versus $29 \%$, respectively $(p=0.389)^{46}$. However, a study was recently performed in 38 pediatric patients with VVS, aged 6 to 13 years, in whom 24-h urine norepinephrine (NE) values analysis was carried out to demonstrate that urine NE high figures are related to a higher response to metoprolol treatment. Said patients were initially compared with a control group of 20 healthy subjects. After 24-h urine NE values were measured in patients with VVS $(31.62 \pm 14.11 \mu \mathrm{g} / 24 \mathrm{~h})$, a significantly high dispersion coefficient was recorded $\left(R^{2}=0.0028\right)$ in comparison with the control group, in which in 24-h urine NE figures were $35.04 \pm 7.28 \mu \mathrm{g} / 24 \mathrm{~h}$, with a low dispersion coefficient $\left(R^{2}=0.0002\right)$. These results demonstrate individual differences between patients with VVS, in whom urine NE quantification has a possible predictive value for metoprolol treatment evaluation. Due to the obtained results, the use of metoprolol was evaluated in the 38 patients with the condition, and it was concluded that patients who show an effective response to metoprolol are linked to 24-h urine NE high levels in comparison with those without treatment response ( $40.75 \pm 12.86$ vs. $21.48 \pm 6.49$, respectively). Similarly, it was established that patients with 24-h urine NE elevated values have a higher supine blood pressure elevation, both systolic and diastolic and that 24-h urine NE values $>34.84 \mu \mathrm{g} / 24 \mathrm{~h}$ are indicators that metoprolol treatment can be effective in pediatric patients, with $100 \%$ specificity and $70 \%$ sensitivity ${ }^{47}$. This opens a door for further studies based on the principles presented in this study.

\section{Interventional treatments}

The use of pacemaker in pediatric patients remains a controversial topic due to the benign nature of the disease, and even in the guidelines there is still controversy regarding this issue. The AHA/ACC/HRS guidelines (2017) for syncope assessment and treatment classify the use of pacemaker with level of evidence Illb, based on two studies conducted in 22 pediatric patients who experienced periods of apnea that sometimes caused seizures secondary to cerebral anoxia, and in whom prolonged periods of asystole ( $>4 \mathrm{~s}$ ) were subsequently documented; after placement of the pacemaker, syncope episodes were reduced by up to $86 \%{ }^{16}$.

There is still insufficient evidence to consider pacemaker as an absolute indication when the patient meets said clinical criteria, and the type of pacemaker to be used has neither yet been studied because both the one-chamber pacemaker with hysteresis and the dual-chamber pacemaker demonstrate similar effectiveness in syncope reduction ${ }^{48.49}$. However, studies comparing both pacemakers are still required, as well as long-term follow-up of these patients.

On the other hand, the European Society of Cardiology (ESC 2018) guidelines do not recommend the use of pacemakers in pediatric patients and neither in young adults; subjects aged $>40$ years are the ideal patients when they meet the criteria for the procedure ${ }^{3}$.

Cardioneuroablation has been proposed as a novel treatment for patients who exhibit a cardioinhibitory-type response. This treatment involves ablation of intra-cardiac parasympathetic ganglionated plexuses, predominantly localized on the posterior wall of the left atrium. The objective is to reduce vagal tone and thus avoid the cardioinhibitory component by increasing heart rate to reduce syncope episodes. Although there are no cohort studies in pediatric patients, some isolated cases such as that reported by Suenega et al. ${ }^{50}$ in a 17-year-old female patient, and the one by Debruyne et al..$^{51}$ in a 16-year-old individual, show promising results, with patients being free of syncope during a 12and a 22-month follow-up, respectively, after the intervention. Despite the good results, studies with larger cohorts are required to consider cardioneuroablation as a therapeutic option for pediatric patients.

\section{Conclusions}

Neurocardiogenic syncope constitutes a diagnostic challenge in pediatrics. On initial evaluation, it is necessary ruling out personal and family-inherited heart 
pathology history in search for sudden death and, in case of suspicion or doubt, referring the patient to the pediatric cardiologist or electrophysiologist is necessary once neurological and psychogenic problems have been ruled out as the primary origin of syncope ${ }^{52}$.

The head-up-tilt-test helps to clarify diagnostic suspicion of neuro-cardiogenic syncope, which is the most common cause of syncope. In pediatric patients, there is still controversy regarding the use of pharmacological challenge during head-up-tilt-test, but various studies have documented its safe use, even though cases of cardiorespiratory arrest have been documented in tilt tests, as well as other adverse effects attributed to use of isoproterenol during pharmacological challenge, although these are mostly studies carried out in adults in whom comorbidities play an important role. The use of nitrates has been shown to be effective and safe in pediatric patients, and sublingual administration facilitates their use and benefits the test, which prevents false-positive results due to stress secondary to the puncture for medication administration. Doctor's fear of using this compound limits the test results, since pharmacological challenge increases sensitivity with a slight specificity reduction.

First-choice treatment is non-pharmacological measures, which involves educating the patient and changing his/her diet (increase in water and salt intake). Pharmacological treatment has been shown to be effective in few studies, specifically in the case of midodrine. Although some recent studies demonstrate that metoprolol can be effective if its use is based on 24-h urine NE quantification, this study opens a field in pharmacological treatment research.

The use of pacemaker to treat neuro-cardiogenic syncope in pediatric patients remains controversial even in syncope guidelines ${ }^{3,15}$ and the paucity of evidence limits its use given that there are no clearly-established implementation criteria. Cardioneuroablation is a promising treatment in patients that show cardioinhibitory response during syncope due to the success reported in isolated cases, and it has been shown to be effective, safe and without syncope recurrence during follow-up. However, further studies are required in this regard aimed at the pediatric population.

\section{Funding}

This research has not received any specific scholarship from public or commercial sector agencies or non-profit entities.

\section{Conflicts of interest}

None.

\section{Ethical disclosures}

Protection of people and animals. The authors declare that no experiments were performed on humans or animals for this investigation.

Confidentiality of data. The authors declare that no patient data appear in this article.

Right to privacy and informed consent. The authors declare that no patient data appear in this article.

\section{References}

1. Driscoll DJ, Jacobsen SJ, Porter CJ, Wollan PC. Syncope in children and adolescents. J Am Coll Cardiol 1997:29:1039-45.

2. Lewis DA, Dhala A. Syncope in the pediatric patient. Pediatr Clin North Am 1999;46:205-19.

3. Brignole M, Moya A, Lange FJ, Deharo JC, Elliott PM, Fanciulli A, et al ESC Guidelines for the diagnosis and management of syncope. Eur Heart J 2018;39:1883-1948.

4. Fish FA, Strasburger JF, Benson DW Jr. Reproducibility of symptomatic response to upright tilt in young patients with unexplained syncope. Am J Cardiol 1992;70:605-9.

5. Moodley M. Clinical approach to syncope in children. Semin Pediatr Neurol 2013;20:12-17

6. Bayram AK, Pamukcu O, Per H. Current approaches to the clinical assessment of syncope in pediatric population. Childs Nerv Syst 2016;32:427-36.

7. Zhang $Q$, Du J, Wang C, Zhongdong D, Li W, Chaoshu T. The diagnostic protocol in children and adolescents with syncope: a multi-centre prospective study. Acta Pediatr 2009;98:879-84.

8. Rivera-Rodríguez L. El niño con síncope. Acta Pediatr Mex 2015;36: 352-60.

9. Zygmunt A, Stanczyk J. Heart rate variability in children with neurocardiogenic syncope. Clin Auton Res 2004;14:99-106.

10. Dalla PR, Kleinmann A, Zysk S, Bechtold S, Netz N. Head-up-tilt testing in children: new perspectives using beat-to-beat blood-pressure monitoring. Images Paediatr Cardiol 2005;7:1-7.

11. Puggioni E, Guiducci V, Brignole M, Menozzi C, Oddone D, Donateo P, et al. Results and complications of the carotid sinus massage performed according to the "method of symptoms". Am J Cardiol 2002;89:599-601.

12. Bartoletti A, Alboni P, Ammirati F, Brignole M, Del Rosso A, Foglia MG et al. "The Italian protocol": a simplified head-up tilt testing potentiated with oral nitroglycerin to assess patients with unexplained syncope. Europace 2000;2:339-42.

13. Parry SW, Reeve P, Lawson J, Shaw EF, Davison J, Norton M, et al. The Newcastle protocols 2008: an update on head-up tilt table testing and the management of vasovagal syncope and related disorders. Heart 2009:95:416-20.

14. Benditt DG, Ferguson DW, Grubb BP, Kapoor WN, Kungler J, Lerman BB. Tilt table testing for assessing syncope. J Am Coll Cardiol 1996;8: 263-75.

15. Shen W-K, Sheldon RS, Benditt DG, Cohen MI, Forman DE, Goldberger ZD, et al. 2017 ACC/AHA/HRS guideline for the evaluation and management of patients with syncope: a report of the American College of Cardiology/ American Heart Association Task Force on Clinical Practice Guidelines and the Heart Rhythm Society. Circulation 2017;136:e60-e122.

16. Vlahos AP, Tzoufi M, Katsouras CS, Barka T, Sionti I, Michalis LK, et al. Provocation of neurocardiogenic syncope during head-up tilt testing in children: comparison between isoproterenol and nitroglycerin. Pediatrics 2007;119:e419-25

17. Kenny RA, O'Shea D, Parry SW. The Newcastle protocols for head-up tilt table testing in the diagnosis of vasovagal syncope, carotid sinus hypersensitivity, and related disorders. Heart 2000;83:564-9.

18. Raviele A. Tilt-induced asystole: a useful prognostic marker or clinically unrelevant finding? Eur Heart J 2002;23:433-7.

19. Maloney JD, Jaeger F, Fouad-Tarazi F, Morris H. Malignant vasovagal syncope: prolonged asystole provoked by head-up tilt. Cleve Clin J Med 1988:55:542-8.

20. Kim PH, Ahn SJ, Kim JS. Frequency of arrhythmic events during head-up tilt in patients with suspected neurocardiogenic syncope or presyncope. Am J Cardiol 2004;94:1491-5. 
21. Wang $\mathrm{CH}$, Hung MJ, Kuo LT, Cherng WJ. Cardiopulmonary resuscitation during coronary vasospasm induced by tilt table testing. Pacing Clin Electrophysiol 2000;23:2138-40.

22. Stevens PM. Cardiovascular dynamics during orthostatis and the influence of intravascular instrumentation. Am J Cardiol 1966;17:211-18.

23. Lai WT, Chen MR, Lin SM, Hwang HK. Application of head-up tilt table testing in children. J Formos Med Assoc 2010;109:641-6.

24. Shen WK, Jahangir A, Beinborn D, Lohse CM, Hodge DO, Rea RF, et al Utility of a single stage isoproterenol tilt table test in adults. A randomized comparison with passive head-up tilt. J Am Coll Cardiol 1999;33: 985-90.

25. Cohen TJ, Chengot T, Chengot M, Catania S, Quan W. A comparison of a single-stage isoproterenol tilt table test protocol with conventional two-stage tilt protocol in patients with syncope. J Invasive Cardio 2002; $14: 430-1$

26. Dindar A, Cetin B, Ertuğrul T, Cantez T. Sublingual isosorbide dinitrate stimulated tilt test for diagnosis of vasovagal syncope in children and adolescents. Pediatr Cardiol 2003:24:270-3.

27. Karacan $\mathrm{M}$, Olgun $\mathrm{H}$, Ceviz $\mathrm{N}$. Head-Up tilt table testing with sublingual isosorbide dinitrate in the diagnosis of vasovagal syncope in children. Eurasian J Med 2008;40:115-18.

28. Saal DP, Thijs RD, van Dijk JG. Tilt table testing in neurology and clinical neurophysiology. Clin Neurophysiol 2016;127:1022-30.

29. Cheshire WP Jr. Syncope. Continuum (Minneap Minn) 2017;23:335-58.

30. Raviele A, Menozzi C, Brignole M, Gasparini G, Alboni P, Musso G, et al. Value of head-up tilt testing potentiated with sublingual nitroglycerin to assess the origin of unexplained syncope. Am J Cardiol 1995;76: 267-72.

31. Aerts AJ, Dendale P. Nitrate stimulated tilt table testing: a review of the literature. Pacing Clin Electrophysiol 2003;26:1528-37.

32. Aerts AJ, Dendale P, Block P, Dassen WR. Reproducibility of nitrate-stimulated tilt testing in patients with suspected vasovagal syncope and a healthy control group. Am Heart J 2005;150:251-6.

33. Swissa M, Epstein M, Paz O, Shimoni S, Caspi A. Head-up tilt table testing in syncope: safety and efficacy of isosorbide versus isoprotereno in pediatric population. Am Heart J 2008;156:477-82.

34. Delépine S, Prunier F, Lefthériotis G, Dupuis J, Vielle B, Geslin P, et al. Comparison between isoproterenol and nitroglycerin sensitized head-upright tilt in patients with unexplained syncope and negative or positive passive head-up tilt response. Am J Cardiol 2002:90:488-91.

35. Prabhu MA, Pillai V, Shenthar J. Comparison of efficacy, pattern of response, occurrence of arrhythmias, and the tolerability of nitroglycerine and isoprenaline as provocative drugs during head-up tilt test. Heart Lung Circ 2017;26:586-92.

36. Chu W, Wang C, Wu L, Lin F, Zou R. Oral rehydration salts: an effective choice for the treatment of children with vasovagal syncope. Pediatr Cardiol 2015;36:867-72.

37. Numata T, Abe H, Nagatomo T, Sonoda S, Kohshi K, Nakashima Y, et al Successful treatment of malignant neurocardiogenic syncope with repeated tilt training program. Jpn Circ J 2000;64:406-9.
38. Reybrouck $\mathrm{T}$, Heidbüchel $\mathrm{H}$, Van de Werf $\mathrm{F}$, Ector $\mathrm{H}$. Tilt training: treatment for malignant and recurrent neurocardiogenic syncope. Pacing Clin Electrophysiol 2000;23:493-8.

39. Krediet CT, van Dijk N, Linzer M, van Lieshout JJ, Wieling W. Maganement of vasovagal syncope: controlling or aborting faints by leg crossing and muscle tensing. Circulation 2002;106:1684-9.

40. Dehghan B, Sabri MR, Mansourian M. Nonpharmacologic treatments alone are enough to prevent the neurally mediated syncope: a 3 years follow-up study. Int J Prev Med. 2019;10:69.

41. Qingyou Z, Junbao D, Chaoshu T. The efficacy of midodrine hydrochloride in the treatment of children with vasovagal syncope. J Pediatr 2006;14:777-80

42. Liu XY, Wang C, Wu LJ, Hu CY, Lin MX, Cui XL, et al. Efficacy of midodrine hydrochloride in the treatment of children with vasovagal syncope. Zhonghua Yi Xue Za Zhi 2009;89:1951-54.

43. Salim MA, Di Sessa TG. Effectiveness of fludrocortisone and salt in preventing syncope recurrence in children: a double-blind, placebo-controlled, randomized trial. J Am Coll Cardiol 2005;45:484-8.

44. Scott WA, Pongiglione G, Bromberg BI, Schaffer MS, Deal BJ, Fish FA, et al. Randomized comparison of atenolol and fludrocortisone acetate in the treatment of pediatric neurally mediated syncope. Am J Cardiol 1995;76:400-2.

45. Müller G, Deal BJ, Strasburger JF, Benson DW Jr. Usefulness of metoprolol for unexplained syncope and positive response to tilt testing in young persons. Am J Cardiol 1993;71:592-5.

46. Zhang Q, Jin H, Wang L, Chen J, Tang C, Du J. Randomized comparison of metoprolol versus conventional treatment in preventing recurrence of vasovagal syncope in children and adolescents. Med Sci Monit 2008;14:199-203.

47. Kong $Q$, Yang X, Cai Z, Pan Y, Wang M, Liu M. Twenty-four-hour urine NE levels as a predictor of the therapeutic response to metoprolol in children with recurrent vasovagal syncope. Ir J Med Sci 2019. [Epub ahead of print]. https://doi.org/10.1007/s11845-019-01979-9.

48. McLeod Ka, Wilson N, Hewitt J, Norrie J, Stephenson JB. Cardiac pacing for severe childhood neutrally mediated syncope with reflex anoxic seizures. Heart 1999:82:721-5.

49. Kelly AM, Porter CJ, McGoon MD, Espinosa RE, Osborn MJ, Hayes DL. Breathholding spells associated with significant bradycardia: successful treatment with permanent pacemaker implantation. Pediatrics 2001; 108:698-702.

50. Suenaga $\mathrm{H}$, Murakami M, Tani T, Saito $\mathrm{S}$. Frequent neurally mediated reflex syncope in a young patient with dextrocardia: efficacy of catheter ablation of the superior vena cava-aorta ganglionated plexus. J Arrhythm 2015;31:172-6.

51. Debruyne P. "Cardio-neuromodulation" with a multielectrode irrigated catheter: a potential new approach for patients with cardio-inhibitory syncope. J Cardiovasc Electrophysiol 2016;27:1110-13.

52. Anderson JB, Willis M, Lancaster $\mathrm{H}$, Leonard $\mathrm{K}$, Thomas $\mathrm{C}$. The evaluation and management of pediatric syncope. Peaditr Neurol 2016; 55:6-13. 